Notes

\title{
Stripping of Cadmium(II) Xanthato Complexes from the Anionic Surfactant Phase of Sodium Dodecylsulfate Gel to the Aqueous Phase
}

\author{
Shoji Tagashira ${ }^{\dagger}$, Yoshiko Murakami, Shouji Otobe and Yoshiaki SaSakI \\ Department of Chemistry, Faculty of Science, Yamaguchi University, Yamaguchi 753, Japan
}

Keywords Stripping, cadmium(II), sodium dodecylsulfate, xanthate

Traditionally, organic solvents, such as benzene or chloroform, have been used for liquid-liquid extraction systems; however, these solvents are often carcinogenic, toxic and cause environmental pollution. Surfactants have a non-volatile nature and are relatively harmless reagents. An aqueous solution containing surfactants exhibits the property of being separated into two phases due to a temperature change or the addition of salts. Based on these phase-separation phenomena, the surfactant-extraction technique was investigated with interest for chemical analyses involving the separation and quantitative determination of a large number of metal ions. ${ }^{1-4}$ To our knowledge, however, there have been no investigations concerning the recovery of the metal ions from the extracts of the surfactant. This process corresponds to the so-called back- or reverseextractions in the conventional liquid-liquid extraction system. We prepared a series of xanthates $(O$-alkyldithiocarbonate, $\mathrm{ROC}(\mathrm{S}) \mathrm{S}^{-}$, abbreviated as $\mathrm{X}^{-}$) as ligands and investigated the extraction and the stripping of Cd(II) in the forms of xanthato complexes between the two phases of an anionic surfactant of sodium dodecylsulfate (SDS) gel and water.

\section{Experimental}

\section{Reagents}

A $0.05 \mathrm{~mol} \mathrm{dm}^{-3}$ stock solution of Cd(II) was prepared by dissolving a weighed amount of cadmium chloride (Kanto Chemicals) in $0.1 \mathrm{~mol} \mathrm{dm}^{-3}$ hydrochloric acid, then titrimetrically standardized with EDTA. We prepared $20 \%(\mathrm{w} / \mathrm{v})$ SDS (Merck) and $25 \%(\mathrm{w} / \mathrm{v})$ sodium chloride solutions by dissolving weighed amounts in water, respectively. The potassium salts of ethyl-(EtX), butyl-(BuX), and hexylxanthate ( $\mathrm{HeX})$, and the sodium salts of octyl- (OcX), decyl- (DeX), dodecyl- (DoX) and tetradecylxanthate( $(\mathrm{TeX})$ were prepared using a previously reported method. ${ }^{5}$ These reagents were recrystallized three times from acetone and $1.0 \times 10^{-2} \mathrm{~mol} \mathrm{dm}^{-3}$ aqueous solutions were prepared. A $500 \mathrm{~cm}^{3}$ buffer solution was prepared by dissolving $30.3 \mathrm{~g}$ of tris(hydroxymethyl)aminomethane (Wako Pure Chemicals) in water and

† To whom correspondence should be addressed. adjusting the $\mathrm{pH}$ to 8.0 with hydrochloric acid. All other chemicals were of analytical grade.

\section{Apparatus}

AAS measurements were made using a Shimadzu AA625-11 flame atomic absorption spectrometer. All pH measurements were made with a Horiba M-7 pH meter and a combination glass electrode.

\section{General procedure}

A solution containing $\mathrm{Cd}(\mathrm{II})$ was transferred to a $10 \mathrm{~cm}^{3}$ centrifuging tube with a graduation line. After the successive addition of $1.0 \mathrm{~cm}^{3}$ of buffer, $1.25 \mathrm{~cm}^{3}$ of SDS and $1.0 \mathrm{~cm}^{3}$ of xanthate solutions, the solution was diluted to $6.0 \mathrm{~cm}^{3}$ with water. After shaking the solution, $4.0 \mathrm{~cm}^{3}$ of a $\mathrm{NaCl}$ solution was added. After centrifugation, the upper aqueous phase was discarded. The SDS phase that remained at the bottom of the tube was diluted to $10 \mathrm{~cm}^{3}$ with water. After phase separation by cooling, the concentration of $\mathrm{Cd}(\mathrm{II})$ in the aqueous phase was measured by AAS.

\section{Results and Discussion}

\section{Phase separation}

An SDS gel phase was generated by the addition of an electrolyte, such as $\mathrm{NaCl}$, or cooling the solution to under its Krafft point temperature. The water content in the gel phase, which was estimated from the reduced weights by drying under a vacuum at $60^{\circ} \mathrm{C}$, was about $80 \%$ when the phase separation was maintained by a method based on the salting out effect. It was about $90 \%$ by a separation method based on the cooling effect. The volume of the gel phase depended on the concentration of SDS, and was about $1.0 \mathrm{~cm}^{3}$ for a $2.5 \%$ SDS solution.

\section{Extraction of xanthate}

Most of the xanthates in the solution were deprotonated at $\mathrm{pH}=8$, and resulted in anionic species of $\mathrm{X}^{-}$. Figure 1 shows the effect of the alkyl chain length of $X^{-}$ on the extraction of the xanthates. While small ligands of EtX, BuX and HeX were hardly extracted into the SDS phase by salting out, the large and hydrophobic xanthates were increasingly extracted. On the other 


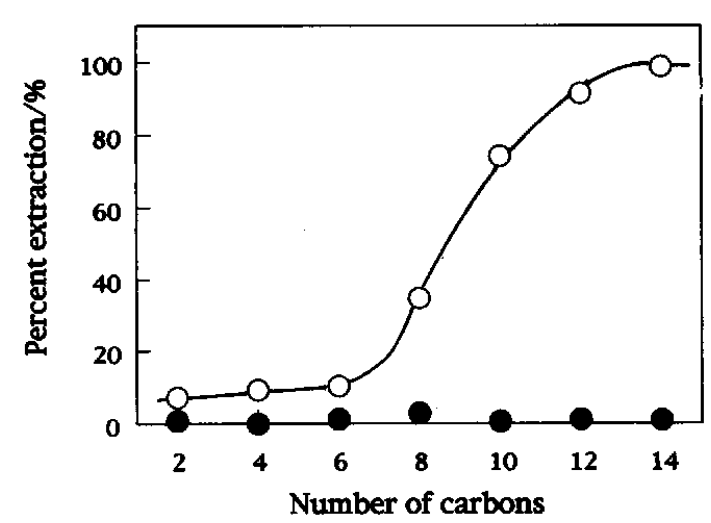

Fig. 1 Effect of the alkyl-chain length on the percent extraction of xanthate. $[\mathrm{SDS}]=2.5 \%(\mathrm{w} / \mathrm{v}),[\mathrm{X}]=2.0 \times 10^{-3} \mathrm{~mol}$ $\mathrm{dm}^{-3}, \mathrm{pH}=8$. $O$ : separation by the addition of $10 \%(\mathrm{w} / \mathrm{v})$ $\mathrm{NaCl}$. : separation by cooling.

hand, all xanthates were not extracted by separation based on the cooling effect. Therefore, TdX and DoX were almost stripped into the aqueous phase, and a part of DeX and OcX after the separation by cooling.

\section{Extraction of complexes}

Cd(II) formed xanthato complexes that were sparingly soluble in both water and SDS micelle. When the micelle was destroyed by the addition of an electrolyte, the complexes were transferred into the SDS phase. The optimal condition of extraction for the Cd(II) complex with DoX was almost the same as that for those with other xanthates, as follows: the concentrations of SDS and $\mathrm{NaCl}$ were $1-4 \%$ and $8-12 \%$, respectively. As shown in Fig. 2, a stable and constant absorbance was obtained at a pH higher than 7 , while the DoX was decomposed and absorbance was reduced with time at a $\mathrm{pH}$ lower than this value.

Figure 3 shows the recovery of $\mathrm{Cd}(\mathrm{II})$ as a function of the concentration of xanthates, where the recovery was calculated by the $\mathrm{Cd}(\mathrm{II})$ quantities measured before and after the stripping. All xanthato complexes were extracted into the SDS phase by salting out. On the other hand, Cd(II) was completely stripped using TeX, DoX and $\mathrm{DeX}$, and was partially stripped using $\mathrm{OcX}$ after phase separation by cooling. None or a small amount of $\mathrm{Cd}(\mathrm{II})$ was stripped with $\mathrm{EtX}, \mathrm{BuX}$ and $\mathrm{HeX}$ into the aqueous phase.

Below the Krafft point temperature, there are no SDS micelles in the aqueous phase, because the solution includes a few surfactants. We previously reported that large xanthates, such as DoX, acted as not only the ligand for metals, but also as surface-active agents. ${ }^{5}$ Large xanthato complexes with $\mathrm{Cd}(\mathrm{II})$, which were stripped from the SDS gel phase, were dissolved by the micelle of xanthates or dispersed as microemulsion in the aqueous phase after separation by cooling. However, the complexes of EtX, BuX and HeX remained in the surfactant phase after phase separation by cooling, because these complexes are insoluble in water. The stripping of

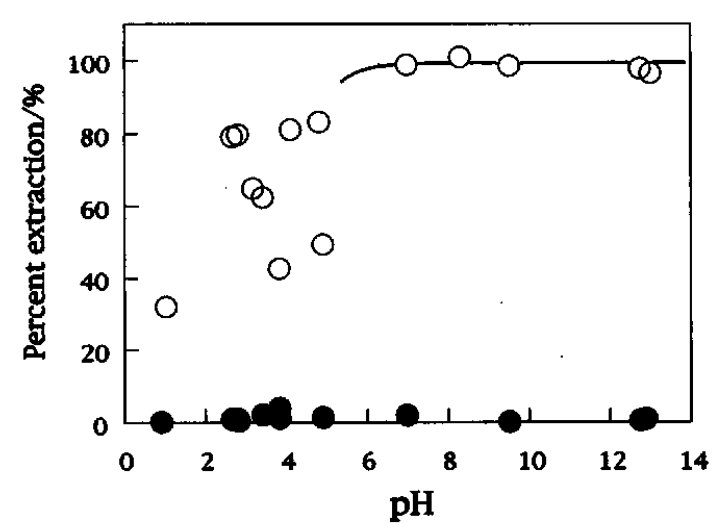

Fig. 2 Effect of the pH on the percent extraction of $\mathrm{Cd}(\mathrm{II})$. $[\mathrm{Cd}(\mathrm{II})]=5.0 \times 10^{-5} \mathrm{~mol} \mathrm{dm}^{-3} . \quad[\mathrm{SDS}]=2.5 \%(\mathrm{w} / \mathrm{v}) . \quad \mathrm{O}$ : with $2.0 \times 10^{-3} \mathrm{~mol} \mathrm{dm}^{-3}$ DoX.

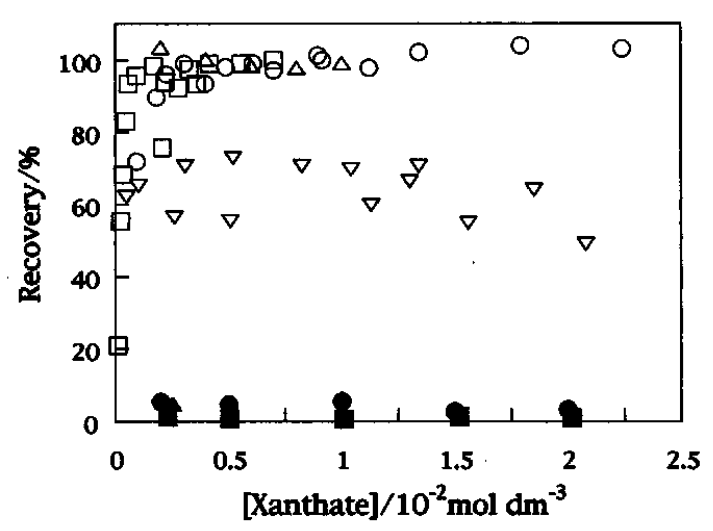

Fig. 3 Effect of the concentration of xanthate on the percent extraction of $\mathrm{Cd}(\mathrm{II}) . \quad \mathrm{X}=(\Delta) \mathrm{TeX},(\square) \operatorname{DoX},(O) \operatorname{DeX},(\nabla)$ $\mathrm{OcX},(\square) \mathrm{HeX},(\Delta) \mathrm{BuX}$ and (O) EtX. $[\mathrm{Cd}(\mathrm{II})]=5.0 \times 10^{-5}$ $\mathrm{mol} \mathrm{d} \mathrm{m}^{-3} . \quad[\mathrm{SDS}]=2.5 \%(\mathrm{w} / \mathrm{v}) . \quad[\mathrm{NaCl}]=10 \%(\mathrm{w} / \mathrm{v})$, $\mathrm{pH}=8$.

Cd(II) was performed with a $2.5 \times 10^{-2} \mathrm{~mol} \mathrm{dm}^{-3}$ EDTA solution after extraction of Cd(II) as the EtX complex. More than $96 \%$ of Cd(II) was recovered. The extraction species seemed to change from $\mathrm{CdX}_{2}$ to the watersoluble $[\mathrm{Cd}(\mathrm{EDTA})]^{2-}$ by the addition of EDTA.

The proposed extraction method can be widely applicable to recover metals in seawater and high-salinity wastewater; it will also be possible to recycle surfactants.

\section{References}

1. E. Pramauro and E. Pelizzetti, "Surfactants in Analytical Chemistry", pp. 393-451, Elsevier, Amsterdam, 1996.

2. S. Tagashira, Y. Murakami, M. Nishiyama, N. Harada and Y. Sasaki, Bull. Chem. Soc. Jpn., 69, 3195 (1996).

3. W. L. Hinze and E. Pramauro, Crit. Rev. Anal. Chem., 24, 133 (1993).

4. T. Saitoh, Y. Kimura, T. Kamidate, H. Watanabe and K. Haraguchi, Anal. Sci., 5, 577 (1989).

5. K. Hayashi, Y. Sasaki, S. Tagashira and N. Mito, Bronseki Kagaku, 35, 413 (1986).

(Received May 29, 1997) (Accepted July 16, 1997) 